EPOS, XIII (1997), pd́gs. 189-208

\title{
UN MODO DE DIÁLOGO INTERTEXTUAL: EL EPÍGRAFE LITERARIO EN CÁNTICO, DE JORGE GUILLÉN
}

JUAN MONTERo

Universidad de Sevilla

\section{RESUMEN}

La utilización de epígrafes literarios, que es una constante en la obra poética de Jorge Guillén, constituye una forma privilegiada del diálogo que el autor mantiene con la tradición poética, antigua y moderna. Ya en Cántico puede comprobarse que no se trata en ningún caso de un recurso accesorio, sino integrado de pleno en la composición del libro. Por eso los encontramos encabezando tanto terminados poemas como secciones del libro e incluso abriendo o cerrando el propio volumen. De esta manera, los epígrafes proporcionan una perspectiva idónea para abordar, en síntesis, el análisis de la aventura creativa, cultural y vital que diseña Cántico en sus sucesivas redacciones, al tiempo que permiten indagaciones estilísticas clarificadoras de la complejidad significativa de los textos poéticos guillenianos.

Al hablar de epígrafe literario me refiero a las citas de otros escritores (aunque también se da la autocita) que un autor propone como encabezamiento o lema de una creación propia, ya sea libro o parte de libro. Se trata, obvia- 
mente, de una forma de llamar la atención del lector, apuntándole o sugiriéndole posibles claves interpretativas del texto que va leer.

El epígrafe plantea un diálogo entre dos textos, uno que se desarrolla íntegramente a la vista del lector y otro que se presenta como fragmento desgajado de una totalidad ausente, pero de algún modo representada. La brevedad, el fragmentarismo, el carácter alusivo son rasgos que contribuyen a que el epígrafe se cargue de significación por diversas vías y se convierta, así, en elemento consustancial al texto que acompaña:

Il fascino maggiore dell'epigrafe consiste proprio nella sua varietà e nelle vastissime opportunita di relazione che l'autore vuole stabilire con il fruitore di essa; a volte si tratta di un sottile gioco ironico o polemico o ammiccante, di un allusione ambigua o insinuante, altre deve accrescere la sensazione, l'emozione. Non è raro il caso in cui lo scrittore si serve di una citaziones desiderando dal suo lettore un collegamento non solo con la stessa, ma con tutto il testo da cui è stata tolta (...). Continua ad essere un brano, un frammento di poesia di un altro autore che, in quanto scelto, diventa in parte anche di chi lo ha assunto e diviene comunque essenziale al nuovo testo .

A ningún lector de Jorge Guillén se le escapa que el recurso al epígrafe literario constituye un rasgo recurrente de su obra, desde Cántico a Final, y de una manera muy destacada en Homenaje, volumen cuya génesis creadora reside precisamente en la glosa de textos ajenos, aludidos y citados de muy diversas maneras ${ }^{2}$. En la perspectiva del estudio general que todo este material requiere, propongo ahora un acercamiento al tema en Cántico, con un doble objetivo. Primero, proporcionar unos datos que, en diverso grado, pueden resultar útiles tanto a los futuros editores y estudiosos del libro como a sus lectores. Y segundo, ahondar por esta vía en la comprensión tanto del proceso creativo de Cántico como de su organización y significación poética.

1 (Montalvo Cessi 1989: 7-8). La autora, que se lamenta de la falta de estudios de este tipo en el campo de la literatura espanfola, aborda el epígrafe como una forma de intertextualidad susceptible de ser englobada tanto en el concepto de intertexto que propone C. Segre (presencia de textos anteriores en un texto dado), o-como hace G. Genette- en el de paratexto, junto con el título, subtitulo y otros signos accesorios que acompanian a un texto.

2 Sobre este aspecto de Homenaje, vid. Schalk, FrITZ (1974), Young, Howard T. (1991), Florit Duran, Francisco (1994), Blecua, Jose Manuel. (1995). De epígrafes poéticos en Aire Nuestro trata especificamente SORIA OLMEDO, ANDREs (1994). Con anterioridad, habían abordado la cuestión MACRI, ORESTE (1976: $411-418$, especialmente 41 1-413 para Cántico) y PRAT, IgNACIO (1974: 17 ss.), a la hora de analizar la estructura de Aire Nuestro. 
La primera redacción de Cántico, aprecida en 1928, constaba de setenta y cinco poemas repartidos en siete secciones carentes de título propio. Figuraban en el libro cuatro lemas, dos de autores franceses (Rimbaud y Valéry), dos de españoles (Góngora y Juan Ramón). Estos últimos aparecían al frente de la sección 5, la de las décimas, mientras aquéllos lo hacían al frente de sendos poemas de las secciones 2 y 6 . Parvo material, todavía, pero ya significativo de la tradición poética en la que el autor quería inscribirse: la de la poesía pura, en armoniosa síntesis de tradición y modernidad, españolismo y europeísmo.

Dentro de las importantes novedades que ofrecía el Cántico de 1936 (ciento veinticinco poemas repartidos en cinco secciones con título propio) algunas afectan a los epígrafes. Éstos siguen siendo cuatro, pero no los mismos. El de Rimbaud es el único que permanece, mientras han desaparecido los de Góngora y Juan Ramón; el de Valéry, por su lado, ha sido sustituido por otro también suyo. Los autores ahora incorporados son San Juan de la Cruz, del que se cita, al frente de la sección primera, un pasaje del Cántico espiritual, que además da título a esa parte del libro: «Al aire de tu vuelo»; y fray Luis de Leon, cuya cita tiene la misma ubicación y protagonismo en la sección segunda, «Las horas situadas». Tales cambios pueden considerarse como solidarios de la nueva orientación que Guillén quiso imprimir a Cántico. Se apunta en ellos (aparte la cuestión personal en el caso de Juan Ramón Jiménez) una matización a la tendencia purista del primer Cántico, del que se salva exclusivamente la cita del poeta más impuro (Rimbaud), en beneficio de una ampliación de los temas y contenidos poéticos ${ }^{3}$. La más acendrada cultura religiosa en su mejor expresión literaria tiene, así, cabida en las citas de los dos clásicos españoles. La nueva cita de Valéry («Je soutenais l'éclat de la mort toute pure», nótese el adjetivo) parece advertimos, sin embargo, que el proceso es de profundización, no de ruptura: «Muerte a lo lejos» pretende, en efecto, depurar a la muerte de sus accidentes para reducirla a su esencia de ley fatal. La síntesis vital y cultural que proponía el primer Cántico queda, pues, asumida y, reinterpretada, se dispone a desplegarse en toda su amplitud.

La decisiva maduración de Cántico entre las ediciones de 1936 y 1945 (las cinco secciones acogen ahora doscientos setenta poemas) alcanza de lleno a los epígrafes del libro. Éstos pasan de cuatro a ventiuno; entre los añadidos hay dieciséis que son del todo nuevos y uno (de Góngora) que ya había figurado en el primer Cántico. Más allá del número, lo primordial reside en el hecho de que las citas entran a formar parte de la propia disposición y estructura de la obra.

${ }^{3}$ Cabe destacar que la cita de Rimbaud será a la postre la única de todas que estara presente en las cuatro redacciones de Cántico. Sobre las relaciones personales y literarias entre Juan Ramón Jiménez y Guillén, vid. ahora MAURER, CRISTOPHER (1994). 
Las encontramos, así, tanto en la apertura (dos) como en el cierre (una) del libro, $\mathrm{y}$ al frente de cada una de las secciones; además, todos estos epígrafes figuraban expresamente en el índice del volumen. En cuanto a los autores, el dato principal es que son mayoritariamente hispanohablantes, españoles en su práctica totalidad. Los hay clásicos: Manrique, Garcilaso, Cervantes (dos veces), el repescado Góngora, Lope, Quevedo y Calderón; pero no les van a la zaga los modernos: Darío, Unamuno, A. Machado (dos), Miró y Lorca (dos). La nómina de las nuevas incorporaciones se completa con Shakespeare y Mallarmé. Se ve, por tanto, que junto a la persistencia del diálogo con otras literaturas -ampliado ahora a la anglofona-, el tercer Cántico persigue sobre todo el enraizamiento en la tradición, pasada y presente, del propia idioma, opción que es solidaria de la orientación poética del libro (el conflictivo entrelazamiento de Naturaleza e Historia) y tiene que ver con la vivencia del poeta desterrado de su patria.

El Cántico de 1950, con sus trescientos treinta y cuatro poemas, no hace sino perfilar y dar forma definitiva al mundo poético previamente elaborado. En el campo de las citas, esto se traduce en una serie de modificaciones de alcance limitado. Así, de las cuatro citas que se suprimen (la de Rubén, una de A. Machado, la de Miró y una de Lorca), las tres primeras son reemplazadas por otras de los mismos autores. Se incorporan, asimismo, cinco nuevas, pertenencientes al Arcipreste de Hita, Cervantes, Walt Whitman, Juan Ramon Jiménez y Alfonso Reyes ${ }^{4}$. A la vez que un ajuste en el diseño de una depurada y variada tradición española (en la que vuelve a tener cabida Juan Ramón Jiménez), los cambios subrayan la dimensión americana del último Cantico, tanto en su vertiente hispánica como en la anglofona. Los nombres de Juan Ramón y Alfonso Reyes aportan, además, la presencia de dos autores vivos, cuya obra se ha hecho a caballo entre España y América. Junto a estos cambios, se producen algunos retoques en citas que ya figuraban en el tercer Cántico.

4 Siguiendo el hilo que ofrece MACRl (1979:413) he podido localizar la cita de ALFONSO REYES entre las páginas de uno de sus ensayos sobre Goethe, el que apareció en el número conmemorativo monográfico de la revista Sur de Buenos Aires el año de 1932. Alfonso Reyes se hizo eco del epigrafe guilleniano en una carta dirigida al poeta el seis de junio de 1951: Cántico -le escribe«...ha ido ascendiendo por su órbita con la luz y la firmeza de una estrella. "Energía de normalidad". De tal suerte se ha convertido en una estructura de la vida espiritual de usted, que inaugura, a mi sentir, una función nueva de la estética, la más legítima. Sea usted mil veces loado»; citado por MAURER, Cristopher (1993: 94). Años más tarde el propio Guillén recordará de nuevo el lema: «"Normalidad como energra" / Pensó el aguerrido con pluma / Creando una categoría. / Tal virtus a la gracia suma / La fuerza que no desafía.» (De «Genio del idioman, $Y$ otros poemas, Buenos Aires, Muchnik, 1971, p. 300). Recuérdese, por otra parte, que Jorge Guillén recibi6 el premio Alfonso Reyes en México el año de 1977. 
Desplazamientos, por ejemplo, de algunas, sobre todo en el cierre del libro: la de Miró que había en 1945 desaparece y su lugar lo ocupan ahora dos (equilibrando las dos que había al principio de la obra): una de Quevedo, la que en 1945 abría la sección quinta, y una de Unamuno, que en 1945 precedía al poema «Mundo en claro» 5 .

El resultado alcanzado, que ya no sufrirá modificaciones, arroja el siguiente balance. Son en total veinticinco epígrafes (otros siete han quedado en el camino $)^{6}$, distribuidos como sigue: cuatro van precediendo, por parejas, las dedicatorias inicial y final respectivamente, desarrolladas ahora como verdaderos poemas; cinco están abriendo cada una de las secciones; y dieciséis aparecen acompañando un total de catorce poemas (hay dos poemas con dos citas cada uno, «Mesa y sobremesa» y «La Florida»). La distribución por secciones no sigue un esquema cerrado, pero se percibe cierta progresión cuantitativa en las secciones centrales: sin contar los epígrafes que abren cada sección, la I contiene una cita, tres (para dos poemas) la II, cuatro la III, cinco (para cuatro poemas) la IV, y tres la V. En cuanto a la naturaleza de las citas, la gran mayoría (veintiuna) son breves fragmentos (uno, dos o excepcionalmente tres versos) de obras poéticas o dramáticas (en el caso de La vida es sueño); hay dos también breves, en prosa; y, finalmente, dos que son meras referencias a un autor u obra, sin cita explícita: la del Quijote que precede a «Noche del caballero" y la mención de A. Machado al frente de «Álamos con río». Por lo que hace a la relación, meramente editorial de momento, entre los poemas y las citas, la casuística es variada. La mayoría de las veces poema y epígrafe entran al unísono en Cántico, pero no faltan excepciones; unas veces el poema precede al epígrafe, y otras (más numerosas) un poema pierde un epígrafe que había tenido en una edición anterior ${ }^{7}$. De los ventidós autores representados quin-

S Otros retoques dignos de mención son la adición de una referencia bibliográfica ( Quijote», I, 13) en el epígrafe cervantino que encabezaba "Los balcones del oriente»; la supresión de una cita machadiana (Castilla, España de los largos ríos.), dejando intacta la mención de su autor en el poema «Álamos con rfo»; y el cambio de «Don Miguel de Unamuno» por «Unamunow a secas en la cita que en $C_{3}$ acompañaba el poema $*$ Mundo en claro» y en $C_{4}$ precede la dedicatoria final.

- Cifra que se eleva a ocho si contamos un epígrafe juanramoniano que acompañaba al romance «Festividad» en la versión suelta publicada en la Revista de Occidente, XLIII (1927), p. 47; la cita era: Dios está azul / (BALADAS DE PRIMAVERA); vid. J. Guillén, Cántico [1936], ed. J. M. Blecua, Barcelona, Labor, 1970, pp. 232-233. Los siete epigrafes desechados figuran al final del Apendice de este trabajo.

${ }^{7}$ Son cinco los poemas que han tenido epígrafe en alguna de las ediciones de Cántico y no lo tienen en la versión final del libro: «A lo largo de las orillas ilustres», con una cita de Ruben Darío en $\mathrm{C}_{3}$; «Ciudad de los estros», que llevaba una cita de Paul Valéry en $\mathrm{C}_{1}$; «Vuelta a empezar», encabezada por un eprgrafe de Unamuno en $C_{3}$; «Tierra y tiempo», que llevaba una cita de A. Machado en $\mathrm{C}_{3}$; la sección VI de «Cara a cara", con una cita de Lorca en $\mathrm{C}_{3}$. 
ce son españoles; de ésos, nueve aparecen abriendo y cerrando libro o sección: Manrique, Garcilaso, San Juan de la Cruz, Fray Luis, Góngora, Lope, Calderón, Quevedo y Unamuno (en este mismo orden) ${ }^{8}$. Encabezando poemas comparecen Juan Ruiz, Cervantes (tres veces), A. Machado (dos veces), Juan Ramón Jiménez, Miró y Lorca. Completan la nómina, también encabezando poemas, dos autores hispanoamericanos (Darío y A. Reyes), tres franceses (Rimbaud, Mallarmé y Valéry) y dos de habla inglesa (Shakespeare y Whitman).

El elenco de autores seleccionados ofrece, en primer lugar, una síntesis de la trayectoria vital y literaria del autor de Cántico, y propone una lectura del libro como fruto a la vez del adentramiento en la tradición del propio idioma y del diálogo vivificador con otras literaturas. No hay duda que, al mismo tiempo, Guillén está elaborando hacia el pasado, su propia tradición poética, conforme a la reflexión borgiana: «...cada escritor crea sus precursores. Su labor modifica nuestra concepción del pasado, como ha de modificar el futuro» ${ }^{9}$. Así lo ha notado Francisco Rico:

La poesía de Guillén es una afirmación literaria de tanta entidad que modifica, sin más, toda la trama de categorías y juicios urdida anteriormente, de forma que nos obliga a revisarla punto a punto con la perspectiva de Aire nuestro. Y, de igual modo que su influencia se advierte a menudo en los contemporáneos, esa revisión nos fuerza a reconocer versos, maneras, tonos de Guillén en los textos del pasado, y ello en una medida que han alcanzado sólo escasos autores del siglo $\mathrm{XX}^{10}$.

En efecto, desde la atalaya de Cántico, los versos puestos en epígrafe de Manrique, Garcilaso, Fray Luis y otros nos parecen ahora anunciadores de los que un día había de escribir el poeta contemporáneo. ¿Cabe imaginar, por ejemplo, un endecasílabo más guilleniano que el de Lope: «sino esencia real que al tacto obliga»? ¿Y qué decir de un sintagma como la «claridad calien-

8 Merece la pena destacar, como un indicio más de la convergencia entre crítica y poesía, que Guillén consideraba canónicos a los siete escritores áureos ahí mencionados: en carta del trece de marzo de 1940 le confiesa a Salinas el deseo de escribir *...un libro sobre los siete poetas espafioles (del Siglo de Oro): Garcilaso, fray Luis, san Juan de la Cruz, Góngora, Quevedo, Lope y Calderón. (El número cabalístico me obliga a dejar fuera al Divino de Sevilla; pero la omisión permite una lista más coherente y nivelada, más justa)» (Pedro Salinas / Jorge Guillén, Correspondencia (1923-1951), ed. A, Soria Olmedo, Barcelona, Tusquets, 1992, p. 226).

9 J. L. BorGes, «Kafka y sus precursotes», Otras inquisiciones, Madrid, Alianza, 1976, p. 109. Cfr. AlAZRAKI, JAIME (1988), con observaciones, entre otras cosas, acerca de intertextualidad y reescritura.

${ }^{10}$ (RICO 1984: 1). Reflexiones que dimanan de la propuesta del mismo RICO, (1983). 
te y cincelada» que Guillén entresaca de Miró? ¿O del «triunfo de las cosas» que encuentra en Whitman? Está claro: de este modo Cántico viene a poner de realce cuanto de guilleniano había (sin que se supiese) en la literatura precedente.

En otro orden de cosas, el conjunto de las citas ofrece un material de gran riqueza para el análisis estilístico pormenorizado del juego dialogico, hecho de réplicas y asentimientos, que se establece entre las citas y los textos a los que acompañan. Me detendré, para finalizar, en esto último, limitándome a destacar los dos procedimientos que me parecen más significativos e interesantes. Uno es el de la semantización afirmativa; otro es el de la simpatía rítmica.

Como no podía ser de otra manera, la apropiación guilleniana de una cita conlleva una tensión semántica como consecuencia del nuevo contexto en que se inserta, lo que desencadena un juego de atracción y resistencia entre los textos que se acoplan ". Dicha tensión se resuelve en la lectura mediante un proceso por el cual la cita se carga de significación positiva en los términos guillenianos de la «fe de vida». Un caso bastante explícito lo tenemos en las dos dedicatorias del libro. La primera, «A mi madre en su cielo», va precedida por dos citas procedentes de sendas elegías. Una, la manriqueña «voluntad placentera» (en morir) ya va en cierto modo contrapesada por la otra, el «puro resplandor» garcilasiano (de la Palabra) que «serena el viento» (de la Historia y la Muerte) ${ }^{12}$. La semantización positiva se completa en el poema/dedicatoria a la madre difunta, donadora del vivir y del lenguaje: la voluntad placentera es ya de vivir como «criatura / Humildemente acorde». En la dedicatoria final ocurre algo parecido. La preceden sendas citas de Quevedo y Unamuno, seguramente los dos agonistas mayores de la poesía castellana. Los epígrafes parecen

$"$ Cfr. las consideraciones de SORIA OLMEDo (1994: 332-333), glosando los planteamientos de A. Compagnon sobre la cita: $\alpha E \mathrm{E}$ hecho es que la cita apela a la competencia del lector, lo fuerza a trabajar sobre la compresencia de dos textos, el citado y el del autor, cuya relación no es de equivalencia ni de redundancia, y abre una "diferencia de potencial" entre ambos. Citar es ex-citar, atraer hacia sí, pero también dejar pasar a un intruso, de modo que cabe cierta negociación del significado. Con un grano de sal, la presencia de las citas da cierta legitimidad a un ejercicio de lectura que se pregunte por esa relación que es diferencia, por ese juego de atracción y resistencias.

12 Rico (1984: 1) va más allá en su análisis de la relación entre la dedicatoria guilleniana y el pasaje manriquefio aludido por el epígrafe: $\alpha E l$ ineludible cotejo entre ambos pasajes caracteriza a Cántico, desde luego, como una singular y aun polémica fe de vida (según realza el subtítulo). Pero la evocación contiene, además, una exégesis de Manrique (prolongada en muchos lugares de Aire nuestro): invita a descubrir en las Coplas el sereno contraste de una voluntad de vida y una voluntad de muerte, donde la segunda no anula a la primera -como a veces se abulta-, sino que la subraya, en tanto que una y otra se revelan como respuestas de identica dignidad y nobleza a unas verdades o imperativos de distinta jerarquía. Y nuestro entendimiento de Manrique no puede ya prescindir de la propuesta guillenianar. 
dialogar entre sí: «AAh de la vida! ¿Nadie me responde?» // «Sumersión en la fuente de la vida, / Recio consuelo" (quizá la secuencia podría alargarse, para empezar con la cita calderoniana que abre la sección V: "¿Quién tuvo dichas heroicas / Que entre sí no diga...» // « ¡Ah de la vida!...»). La angustia quevedesca ante el paso del tiempo y la inanidad de lo vivido encuentra su contrapeso en la propuesta unamuniana de sumersión en el manantial de la vida, que en el poema «En el desierto» consiste -conviene subrayarlo- en un retiro eremítico a la búsqueda de Dios. Ahí opera justamente la reinterpretación guilleniana, haciendo que sea la vida misma, exaltada al nivel de la poesía, la fuente inagotable y fabuladora: plenitud del ser consumada en la palabra compartida con el lector amigo ${ }^{13}$.

Por lo que hace a la simpatía rítmica, me detendré en dos ejemplos. En otra ocasión (MONTERO: 1985) he sugerido que el primer verso de «Más allà, poema inicial de Cántico, está animado por un patrón fónico y rítmico que late en la cita de San Juan de la Cruz que abre la sección primera del libro: «Por el otero asoma / Al aire de tu vuelo» (repárese en que Guillén ha recortado el segundo verso para dejarlo en heptasílabo) ${ }^{14}$. El aleteo de la paloma sanjuanista anima el incipit de Cántico: en «El alma vuelve al cuerpo» resuenan los ecos de «Al aire de tu vuelo»; o todavía: «Al aire de tu vuelo» / «El alma vuelve al cuerpo». La matriz fono-rítmica engendra un ritmo capaz de salvar el hiato amenazador de la noche y la nada:

(El alma vuelve al cuerpo,

Se dirige a los ojos

Y choca.) - ¡Luz! Me invade

Todo mi ser. ;Asombro!

Las resonancias vuelven a ser nítidas cinco coplas más abajo:

Una seguridad

Se extiende, cunde, manda,

El esplendor aploma

La insinuada mañana.

13 A propósito del lema quevedesco apunta con razón Young (1991: 375): "As a conclusion to the first complete version of Cántico, Guillén appended Quevedo's dire question “ $¡ A$ h de la vida! ¿Nadie me responde?" (All of Cántico, of course, is a reponse on behalf of la vida to Quevedo's baroque pessimism.) » De la respuesta a textos o ideas ajenos y su plasmación textual se ocupa Quintana Docio, Francisco (1995).

14 Las citas que siguen de «Más allá» proceden de Jorge Guillén, Aire nuestro. Cántico, Barcelona, Barral, 1977, pp. 26-27. 
Estrofa que recoge la rima -oma presente en «asoma» e inscribe en anagrama el término latente: paloma / aploma. Por la luz, mensajera venida del cielo, la mañana pasa de insinuarse a cargarse de sentido, se hace grávida de realidad, late ya en pulsaciones:

Y la mañan pesa.

Vibra sobre mis ojos.

Un análisis similar puede aplicarse en el caso del soneto «Hacia el poema», precedido por una cita de Juan Ruiz, Arcipreste de Hita. También aquí Guillén ha recortado el verso ajeno, haciéndolo de alejandrino endecasílabo y desentrañándole, a la vez, un ritmo dactílico, que se convierte en compás corroborador de lo que el verso dice: «...mi corazón de trovar non se quita». Dada la pauta, el soneto arranca - «Siento que un ritmo se me desenlaza»- evocando el viejo esquema de gaita gallega con el que ha vibrado el castellano desde la Edad Media $-y$ del que se valio Guillen singularmente en la sección III de «Anillo» ${ }^{15}$. Late el verso; el ritmo se hace palabra y vence al barullo caótico:

El son me da un perfil de carne y hueso.

La forma se me vuelve salvavidas.

Hacia una luz mis penas se consumen.

La jovialidad creativa del Arcipreste queda así incorporada y redimensionada por el poeta moderno como voluntad afirmativa de ser frente a la destrucción y el dolor.

Ejemplos como los que preceden son, en fin, suficientes por sí mismos para hacer manifiesto que Guillén ha apurado hasta el límite las posibilidades que le brindaba el diálogo intertextual implicado por el epígrafe. Se corrobora así desde una perspectiva diferente algo que ya sabíamos: que, en su formulación de un clasicismo contemporáneo, la poética guilleniana abraza los márgenes de la lectura y la escritura, de la tradición y el presente, de la crítica y la poesía.

\section{APÉNDICE}

Siguen ahora los epígrafes literarios de Cántico, en una doble relación. Primero, los que figuran en versión final del libro, numerados según el orden

15 La lectura conforme al patrón dactílico tiene, por otra parte, la virtualidad de resaltar en el verso el pronombre me -pese a su condición prosódica de átono-, destacando la carga de significado que conlleva por su condición de dativo ético. 
de aparición en el volumen. Segundo, los que figuraron alguna vez en el libro pero no pasaron a dicha versión última, numerados por orden cronológico de aparicion y precedidos de un asterisco. Tras cada epígrafe se indica su ubicación en Cántico y la referencia bibliografica pertinente.

\section{EPIGRAFES QUE FIGURAN EN C 4}

\section{Con voluntad placentera / JORGE MANRIQUE}

$\mathrm{C}_{3}:$ En página aparte, entre la dedicatoria «A mi madre, / en su cielo» y el núm. 2 de esta relación; ambos lemas preceden, pues, el título de la sección «Al aire de tu vuelo»

$\mathrm{C}_{4}$ : En página aparte, junto con el núm. 2, entre el título «Dedicatoria inicial" y su desarrollo como poema.

«Y consiento en mi morir / con voluntad placentera / clara y pura, / que querer hombre vivir / cuando Dios quiere que muera / es locura» (Coplas a la muerte de su padre, vv. 451-456; en Jorge Manrique, Poesia, ed. V. Beltrán, estudio preliminar de P. Le Gentil, Barcelona, Crítica, 1993, p. 174).

2. Que el puro resplandor serena el viento. / GARCILASO

$\mathrm{C}_{3}$ : En página aparte, entre el núm. 1 y el título de la sección primera.

$\mathrm{C}_{4}$ : En página aparte, junto con el núm. 1, entre el título «Dedicatoria inicial» y su desarrollo como poema.

[Garcilaso a Boscan] «No tienes que temer el movimiento / de la fortuna con soplar contrario, / que el puro resplandor serena el viento." (Elegía II, vv. 154-156; en Garcilaso de la Vega, Obra poética y textos en prosa, ed. B. Morros, estudio preliminar de R. Lapesa, Barcelona, Crítica, 1995, p. 113).

3. Por el otero asoma / Al aire de tu vuelo. / SAN JUAN DE LA CRUZ

$C_{2}:$ En página aparte, entre la dedicatoria «A mi madre, / en su cielo» y el poema-prólogo «Advenimiento».

$\mathrm{C}_{3} / \mathrm{C}_{4}$ : En página aparte, entre el título « $\mathrm{Al}$ aire de tu vuelo» de la sección primera y el poema «Más alla». 
« Apártalos, Amado, / que voy de vuelo! [ESPOSO] Vuélvete, paloma, / que el ciervo vulnerado / por el otero asoma / al aire de tu vuelo y fresco toma.» (Cantico espiritual, vv. 61-65.; en San Juan de la Cruz, Cántico espiritual. Poesías, ed. C. Cuevas García, Madrid, Alhambra, 1979, p. 123).

4. claridad caliente y cincelada. / GABRIEL MIRÓ

$\mathrm{C}_{4}$ : Encabeza el poema «Jardín en medio».

«Tocan las campanas delirantemente. Las torres semejan molinos con las velas hinchadas y joviales. Van pasando unas nubes muy grandes y bajas, de blancura de harina y espumas, frescas, pomposas; y la ciudad, los huertos, los sembrados, los rediles y alcores se apagan, se enfrian a trozos; y en seguida vuelven a la claridad caliente y cincelada. (...) Ornamentos de tisú blanco y de oro; nieblas retorcidas de incienso, cánticos y clamores triunfales de órgano, júbilo magnífico del Gloria in excelsis... Y de pronto, se duermen las campanas; y en el día estático, ya todo azul, comienza un coloquio de gorriones, de niños y jardines. Un águila que pasaba se ha quedado mirando la quietud del valle; después ha seguido volando, todo el cielo callado para sus alas rubias.» (Epígrafe «Jueves Santo», sección «Tablas del calendario entre el humo dormido", El humo dormido; en G. Miro, Obras completas, Madrid, Biblioteca Nueva, 1943, p. 635).

5. Da el hombre a su labor sin ningún miedo / las horas situadas. / FRAY LUIS DE LEON

$\mathrm{C}_{2}:$ En página aparte, entre el tútulo «Las horas situadas» de la sección segunda y el poema «Primavera delgada».

$C_{3} / C_{4}$ : En página aparte, entre el título «Las horas situadas» de la sección segunda y el poema «Paso a la aurora».

«...Tú nos das la noche escura, / en que salen las fieras. / Despiertas el aurora, y de consuno / se van a sus moradas. / Da el hombre a su labor sin miedo alguno / las horas situadas. / C Cuán nobles son tus hechos y cuán llenos / de tu sabiduría!» («Psalmo 103 Benedic, anima mea», vv. 45-54; en Poesía completa, ed. José Manuel Blecua, Madrid, Gredos, 1990, pp. 522-23). 
6. El sol aumenta / su intima influencia. / RUBÉN DARÍO

$\mathrm{C}_{4}$ : Encabeza, junto con el núm. 7, el poema «Mesa y sobremesa».

«iDivina Estación! ¡Divina / Estación! Sonríe el alba / más dulcemente. La cola / del pavo real exalta / su prestigio. El sol aumenta / su íntima influencia; y el arpa / de los nervios vibra sola.» («Por el influjo de la primavera», vv. 32-38, Cantos de vida y esperanza; en R. Darío, Poesías completas, ed. A. Méndez Plancarte con adiciones de A. Oliver Belmás, Madrid, Aguilar, 1967, p. 653).

7. ...energía de normalidad. / ALFONSO REYES

$\mathrm{C}_{4}$ : Encabeza, junto con el núm. 6, el poema «Mesa y sobremesa».

«Nunca se insistirá lo bastante: el jinete que quiere todo el rendimiento de su caballo, necesita desarrollar prodigios de equilibrio. Nada más riesgoso y atlético que la energía de normalidad. Para dar todas las posibilidades a su espíritu, Goethe moverá tierra y cielo». («Rumbo a Goethe», Sur, 5 (1932), p. 34).

\section{Corroborating forever the triumph of things. / WALT WHITMAN}

$\mathrm{C}_{4}:$ Encabeza el poema «El desterrado».

«Splendor of ended day floating and filling me, / Hour prophetic, hour resuming the past, / Inflating my throat, you divine average, / You earth and life till the last ray gleams I sing. / Open mouth of my soul uttering gladness, / Eyes of my soul seeing perfection, / Natural life of me faithfully praising things, / Corroborating forever the triumph of things.» («Song at Sunset», vv. 1-8, seccion «Songs of Parting», Leaves of Grass, ed. Sculley Bradley y Harod W. Blodgett, New YorK - London, W. W. Norton \& Company, 1973, p. 494).

9. Otro instrumento es quien tira / De los sentido mejores. / DON LUIS DE GÓNGORA

$C_{1}$ : En página aparte, junto con el núm. *2, inaugura la sección 5 , sin título. El primer poema de dicha sección era entonces «El ruiseñor». 
$\mathrm{C}_{3} / \mathrm{C}_{4}$ : En página aparte, entre el título «El pájaro en la mano» de la sección tercera y el poema «A eso de las cuatro».

«Lo artificioso que admira, / y lo dulce que consuela, / no es de aquel violín que vuela / ni de esotra inquieta lira; / otro instrumento es quien tira / de los sentidos mejores, / no son todos ruiseñores / los que cantan entre las flores, / sino campanitas de plata, / que tocan a la alba; / sino trompeticas de oro, / que hacen la salva / a los soles que adoro.» (L. de Góngora, Letrillas, ed. Robert Jammes, Madrid, Castalia, 1980, p. 44).

10. ...mi corazón de trovar non se quita / JUAN RUIZ

$\mathrm{C}_{3} / \mathrm{C}_{4}$ : Encabeza el soneto «Hacia el poema».

«Yo, Johan Ruiz, el sobredicho açipreste de Hita, / pero que mi coraçón de trobar non se quita, / nunca fallé tal dueña como a vós Amor pinta, / nin creo que la falle en toda esta cohita." (Juan Ruiz, Libro de Buen Amor, c. 575; ed. Alberto Blecua, Madrid, Catedra, 1992, p. 148).

\section{And all in war with Time for love of you / SHAKESPEARE}

$\mathrm{C}_{3} / \mathrm{C}_{4}$ : Encabeza el poema «Mundo continuo»

"When I consider everything that grows / Holds in perfection but a little moment, / (...) Then the conceit of this inconstant stay / Sets you most rich in youth before my sight, / Where wasteful time debateth with decay / To change your day of youth to sullied night; / And all in war with time for love of you, / As he takes from you, I engraft you new» (Soneto 15, vv. 1-2 y 9-14; en William Shakespeare: Sonetos de amor, ed. y trad. de A. García Calvo, Barcelona, Anagrama, 1974, p. 66).

12. Une rose dans les tenèbres / MALLARMÉ

$\mathrm{C}_{3} / \mathrm{C}_{4}:$ Encabeza el poema «Cierro los ojos».

«Le pur vase d'aucun breuvage / Que l'inexhaustible veuvage / Agonise mais ne consent, / Naïf baiser des plus funebres! / À rien expirer annonçant / 
Une rose dans les tenèbres.» (soneto «Surgi de la croupe et du bond», vv. 9-14; en Oeuvres completes, ed. H. Mondor y G. Jean-Aubry, París, Gallimard, 1945, p. 74).

\section{Je soutenais l'éclat de la mort toute pure / PAUL VALÉRY}

$\mathrm{C}_{2}$ : Encabeza el soneto «Muerte a lo lejos», integrado entonces en la sección «Aquí mismo».

$\mathrm{C}_{3} / \mathrm{C}_{4}$ : Encabeza el poema «Muerte a lo lejos», ubicado ya en «El pájaro en la mano», justo detrás de «Cierro los ojos».

«De l'âme les apprêts sous la tempe calmée, / Ma mort, enfant secrète et déjà si formée, / Et vous, divins dégoûts qui me donniez l'essor, / Chastes éloignements des lustres de mon sort, / Ne fates-vous, ferveurs, qu'une noble durée? / Nulle jamais des dieux plus près aventurée / N'osa peindre à son front leur souffle ravisseur, / Et de la nuit parfaite implorant l'épaisseur, / Prétendre par la lèvre au suprême murmure... / [otro grupo estrofico] Je soutenais l'éclat de la mort toute pure / Telle j'avais jadis le soleil soutenu...» (La jeune parque, vv. 361-371; en Paul Valéry, Oeuvres, ed. J. Hytier, París, Gallimard, 1957, pp. 106-107).

14. No es esto filosofica fatiga, / Transmutación sutil o alquimia vana / Sino esencia real que al tacto obliga / LOPE

$\mathrm{C}_{3} / \mathrm{C}_{4}$ : En página aparte, entre el título «Aquí mismo» de la sección cuarta y el poema «Los balcones del Oriente».

«¡Oh, qué secreto, damas; oh galanes / qué secreto de amor; oh, qué secreto, / qué ilustre idea, qué sutil conceto! / ¡Por Dios que es hoja de me fecit Ioanes! / Hoy cesan los melindres y ademanes, / todo interés, todo celoso efeto; / de hoy más Amor será firme y perfeto, / sin ver jardines ni escalar desvanes. / No es esto filosófica fatiga, / trasmutación sutil o alquimia vana / sino esencia real que al tacto obliga. / Va de secreto, pero es cosa llana. / Q Que quiere el buen letor que se le diga? / Pues váyase con Dios hasta mañana.» (Soneto «A un secreto muy secreto», Rimas... del Licenciado Tomé Burguillos; en Lope de Vega, Obras poéticas, ed. J. M. Blecua, Barcelona, Planeta, 1983, p. 1371). 
15. Mas apenas comenzó a descubrirse / el día por los balcones del Oriente... I "Quijote», I, 13

$\mathrm{C}_{3} / \mathrm{C}_{4}$ : Encabeza el poema «Los balcones del Oriente»; recuérdese ahora que en $\mathrm{C}_{3}$ constaba «CERVANTES» y no la referencia bibliográfica.

«Mas apenas comenz6 a descubrirse el día por los balcones del Oriente, cuando los cinco de los seis cabreros se levantaron y fueron a despertar a don Quijote, y a decille si estaba todavía con proposito de ir a ver el famoso entierro de Grisostomo, y que ellos le harían compañía.» (M. de Cervantes, Don Quijote de la Mancha, ed. J. B. Avalle-Arce, Madrid, Alhambra, 1983, pp. 165-166).

16. I'ai heurté, savez-vous? d'incroyables Florides. / RIMBAUD

$\mathrm{C}_{1} / \mathrm{C}_{2} / \mathrm{C}_{3}$ : encabeza el poema «La Florida».

$\mathrm{C}_{4}$ : encabeza, junto con el núm. 17, el poema «La Florida».

«J'ai heurté, savez-vous, d'incroyables Florides / Mêlant aux fleurs des yeux de panthères à peaux / D'hommes! Des arcs-en-ciel tendus comme des brides / Sous l'horizon des mers, à des glauques troupeaux!» («Le bateau ivre», vv. 45-48; en A. Rimbaud, Oeuvres complètes, ed. A. Adam, París, Gallimard, 1972, p. 67).

17. Todas las rosas son la misma rosa. / JUAN RAMÓN JIMÉNEZ

$\mathrm{C}_{4}$ : encabeza, junto con el núm. 16, el poema «La Florida».

«Todas las rosas son la misma rosa, amor, la única rosa. / Y todo queda contenido en ella, breve imajen del mundo jamor! la única rosa.» («La única rosa», Forma del huir (1917-1924); en Leyenda, ed. A. Sanchez Romeralo, Madrid, CUPSA, 1978, p. 483).

18. Libre naci y en libertad me fundo. / CERVANTES

$\mathrm{C}_{3} / \mathrm{C}_{4}$ : encabeza el poema «Tarde mayor»

«Del campo son y han sido mis amores; / Rosas son y jazmines mis cadenas; / Libre nać y en libertad me fundo.» (Terceto final de un soneto que can- 
ta Gelasia en el libro VI de La Galatea; ed. A, Rey Hazas y F. Sevilla Arroyo, Madrid, Alianza, 1996, p. 431).

19. «Quijote», I, 20

C4: Encabeza el poema «Noche del caballero».

20. ¿Quién tuvo dichas heroicas / Que entre sí no diga... / CALDERóN

$C_{3}$ : Encabeza el soneto «Vuelta a empezar».

$\mathrm{C}_{4}$ : En página aparte, entre el título «Pleno ser» de la sección quinta y el poema «Mundo en claro».

[Segismundo en aparte] «¿Quién tuvo dichas heroicas / que entre sí no diga, cuando / las revuelve en su memoria: / "sin duda que fue soñado / cuanto vi"?..." (P. Calderón de la Barca, La vida es sueño, III, vv. 2973-77; ed. E. Rull, Madrid, Taurus, 1992, p. 223).

\section{Eres tú quien florece y resucita. / ANTONIO MACHADO}

$\mathrm{C}_{4}$ : Encabeza el poema «Mundo en claro».

«Nubes, sol, prado verde y caserío / en la loma, revueltos. Primavera / puso en el aire de este campo frío / la gracia de sus chopos de ribera. / Los caminos del valle van al río / y allí, junto del agua, amor espera. / ¿Por ti se ha puesto el campo ese atavío / de joven, oh invisible compañera? / ¿Y ese perfume del habar al viento? ¿Y esa primera blanca margarita?... / ¿Tú me acompañas? En mi mano siento / doble latido; el corazón me grita, / que en las sienes me asorda el pensamiento: / eres tú quien florece y resucita.» («Primaveral», De un Cancionero apócrifo [1924-1936]; en Poesías completas, ed. crítica de Oreste Macrì con la colaboración de Gaetano Chiappini, Madrid, Espasa-Calpe / Fundación Antonio Machado, 1988, p. 675).

\section{2. (Antonio Machado)}

$\mathrm{C}_{4}$ : Encabeza el poema «Álamos con río»; sustituye al núm. *5, que figuraba en $\mathrm{C}_{3}$. 
23. Lo demás es lo otro: viento triste, / Mientras las hojas huyen en bandadas I FEDERICO GARCÍA LORCA

$\mathrm{C}_{3}$ : Encabeza la sección I de «Cara a Cara»; véase más abajo núm. *6.

$\mathrm{C}_{4}$ : Encabeza el poema «Cara a cara».

"Yo no quiero más que una mano, / una mano herida, si es posible. / (...) Lo demás todo pasa. / Rubor sin nombre ya. Astro perpetuo. / Lo demás es lo otro; viento triste, / mientras las hojas huyen en bandadas.» («Casida de la mano imposible», Sección "Casidas», El diván del Tamarit; en Federico García Lorca, Obras completas, ed. A. del Hoyo, prólogo de J. Guillén, Madrid, Aguilar, 1989, vol. I, p. 594).

24. ¡Ah de la vida! ¿Nadie me responde? / QUEVEDO

$\mathrm{C}_{3}$ : En página aparte, entre el título «Pleno ser» de la sección quinta y el poema «Mundo en claro».

$\mathrm{C}_{4}$ : En página aparte, con el núm. 25, entre el título «Dedicatoria final» $\mathrm{y}$ su desarrollo como poema.

(Primer verso del soneto «Represéntase la brevedad de lo que se vive y cuán nada parece lo que se vivio»; en F, de Quevedo, Poesía original completa, ed. J. M. Blecua, Barcelona, Planeta, 1981, p. 4).

25. Sumersion en la fuente de la vida, / Recio consuelo! / UNAMUNO

$C_{3}$ : Encabeza el poema «Mundo en claro»; recuérdese que aquí ponía DON MIGUEL DE UNAMUNO.

$\mathrm{C}_{4}$ : en página aparte, con el núm. 24 , entre el título «Dedicatoria final» y su desarrollo como poema.

« Casto amor de la vida solitaria, / rebusca encarnizada del misterio, / sumersión en la fuente de la vida, / recio consuelo! / Apartaos de mí, pobres hermanos, / dejadme a solas con mi propio sino, / sin compañero. / Quiero ir allí, a perderme en sus arenas / solo con Dios, sin casa y sin sendero, / sin arboles, ni flores, ni vivientes, / los dos señeros...» («En el desierto», vv. 1-12, de la sección «Salmos», Poesías, 1907; en Miguel de Unamuno, Poesía completa, ed. A. Suárez Miramón, Madrid, Alianza, 1987, vol. I, p. 121). 


\section{EPIGRAFES QUE NO FIGURAN EN $\mathrm{C}_{4}$}

\section{*1. La belle devant nous / Se sent les jambes pures. / PAUL VALÉRY}

$\mathrm{C}_{1}$ : Encabeza el poema «Ciudad de los estíos», perteneciente entonces a la sección 2.

[Hablan las columnas] «Servantes sans genoux, / Sourires sans figures, / La belle devant nous / Se sent les jambes pures. / Pieusement pareilles, / Le nez sous le bandeau / Et nos riches oreilles / Sourdes au blanc fardeau, / Un temple sur les yeux / Noirs pour l'éternité, / Nous allons sans les dieux / À la divinité!» («Cantique des Colonnes», vv. 36-44, de Charmes; en P. Valéry, Oeuvres, ed. cit., p. 117).

\section{*2. ... que así es la rosa! / Juan Ramón JIMÉNEZ}

$\mathrm{C}_{1}$ : En página aparte, junto con el núm. 8 , inaugura la sección 5 , sin título. El primer poema de dicha sección era entonces «El ruiseñor».

«iNo le toques ya más, que así es la rosa!» («El Poema», Piedra y cielo; en J. R. Jiménez, Leyenda, ed. cit., p. 449).

*3. ...cara Lutecia! / R. D.

$\mathrm{C}_{3}$ : Encabeza el poema «A lo largo de las orillas ilustres».

« ¡Los bárbaros, Francia! ¡Los bárbaros, cara Lutecia!» («A Francia», v. 1, Cantos de vida y esperanza; en R. Dario, Poesías completas, ed. cit., p. 709).

*4. Castilla, de largos ríos. / ANTONIO MACHADO

$C_{3}$ : Encabeza el romance «Tierra y tiempo».

"La hermosa tierra de España / adusta, fina y guerrera / Castilla, de largos ríos, / tiene un puñado de sierras / entre Soria y Burgos como / reductos de fortaleza, / como yelmos crestonados, / y Urbión es una cimera.» (Poema II de la sección «Otros días» de «La tierra de Alvargonzález», Campos de Castilla; en A. Machado, Poesias completas, ed. cit., pp. 523-24). 
*5. Castilla, España de los largos ríos. / ANTONIO MACHADO

$\mathrm{C}_{3}$ : Encabeza el romance «Álamos con río».

«Con este libro de melancolía, / toda Castilla a mi rincón me llega; / Castilla la gentil y la bravía, / la parda y la manchega. / Castilla, España de los largos ríos / que el mar no ha visto y corre hacia los mares; / Castilla de los páramos sombríos, / Castilla de los negros encinares!» (Poema CXLIII «(Desde mi rincón)», vv. 1-8, Campos de Castilla; en A. Machado, Poesías completas, ed. cit., p. 591).

*6. ¡Oh, sí! Yo quiero. ¡Amor, amor! Dejadme. / FEDERICO GARCÍA LORCA

$\mathrm{C}_{3}$ : Encabeza la sección VI de «Cara a cara».

«Sí, tu niñez ya fábula de fuentes. / Alma extraña de mi hueco de venas, / te he de buscar pequeña y sin raíces. / iAmor de siempre, amor, amor de nunca! / ¡Oh, sí! Yo quiero. ¡Amor, amor! Dejadme. / No me tapen la boca los que buscan / espigas de Saturno por la nieve / o castran animales por un cielo, / clínica y selva de la anatomía. / Amor, amor, amor. Niñez del mar.» («Tu infancia en Menton», vv. 29-38, seccion «Poemas de la soledad en Columbia University», Poeta en Nueva York; en Obras completas, ed. cit., vol. I, p. 453).

*7. ... quizá por la palabra / se me diese la plenitud de la contemplacion. I GABRIEL MIRÓ

$\mathrm{C}_{3}$ : Precede, en página aparte, la «Dedicatoria Final».

«Sigüenza va recordando (...). Tenía conciencia de mi emoción, sin atribuirle a esa felicidad de sentirme a mí mismo ninguna categoría lírica; toda se guardaba en la delicia de mis ojos y de alguna palabra derretida en mi paladar y en mi lengua; quizá por la palabra se me diese la plenitud de la contemplación.» (Epígrafe «El barranco. Ifach», sección «Bardells y la familia de luto», Años y leguas; en G. Miró, Obras completas, ed. cit., p. 1023). 


\section{Bibliografia (Fuentes Secundarias)}

AlAZRAKI, JAMME (1988): «La modernidad de Borges y el nuevo lenguaje crítico», $L a$ Torre, II, pp. 569-581.

Blecua, Jose MANUEl (1995): «Al margen de Homenaje», Jorge Guillén. El hombre y la obra, ed. A. Piedra y F. J. Blasco Pascual, Valladolid, Universidad de Valladolid / Fundación Jorge Guillén, pp. 25-40.

Florit Durán, Francisco (1994): «Jorge Guillén y su Homenaje a los clásicos del Siglo de Oro», La claridad en el aire. Estudios sobre Jorge Guillén, ed. F. J. Díez de Revenga y M. de Paco, Murcia, Obra Cultural Caja Murcia, pp. 175189.

MACRI, ORESTE (1976), La obra poética de Jorge Guillén, Barcelona, Ariel.

MaUrer, Cristopher (1993): «Alfonso Reyes y Jorge Guillén: «Normalidad como energía»», Boletín de la fundación García Lorca, 13/14, pp. 91-113.

(1994): «Más allá de Eco y Narciso: J.R.J. y Jorge Guillén», La claridad en el aire. Estudios sobre Jorge Guillén, ed. F. J. Díez de Revenga y M. de Paco, Murcia, Obra Cultural Caja Murcia, pp. 207-223.

Montalto Cessi, Donatella (1989): «Uno specchio per i testi: l'epigraphe letteraria nel '700 spagnolo», Quaderni di Letterature Iberiche e Iberoamericane, 9/10, pp. 5-32.

MONTERO, JuAN (1985): «La primera estrofa de Cántico», Le discours poétique de Jorge Guillén, Burdeos, Presses Universitaires de Bordeaux, pp. 147-166.

Prat, Ignacio (1974): «Aire nuestro de Jorge Guillén, Barcelona, Planeta.

QUINTANA DOCIO, FRANCISCO (1995): «Replicas intertextuales elocutivas en la poesía de Jorge Guillén», Jorge Guillén. El hombre y la obra, ed. A. Piedra y F. J. Blasco Pascual, Valladolid, Universidad de Valladolid / Fundación Jorge Guillén, pp. 221-243.

Rico, Francisco (1983): «Literatura e Historia de la Literatura», Boletín informativo de la Fundación Juan March, 127, pp. 3-16.

(1984): «La obra crítica de Jorge Guillén», El País Libros, 225, pp. 1 y 8.

SCHALK, FrITZ (1974): «Jorge Guillén ante la tradición poética: Homenaje», Revista de Occidente, 130, pp. 117-128.

SORIA OlmEdo, ANDRÉs (1994): «Con aire blanco en torno": glosas a los epígrafes iniciales de Aire Nuestro", La claridad en el aire. Estudios sobre Jorge Guillén, ed. F. J. Díez de Revenga y M. de Paco, Murcia, Obra Cultural Caja Murcia, pp. 331-339.

Young, Howard T. (1991): «Texts and Intertexts in Jorge Guillén's Homenaje», Comparative Literature, 43, pp. 370-382. 